\title{
WHY IS THE ENVIRONMENTAL JUSTICE MOVEMENT SO MUCH STRONGER IN THE USA THAN IN EUROPE?
}

\author{
By Daniel Lobo
}

\begin{abstract}
Although there is a vast amount of critically influential knowledge developed by a long history of strong US environmental justice movements (EJM) from which Europe and the rest of the world can learn, in a time of strong post-neoliberal tendencies in Europe it becomes important to understand the nature of this knowledge, its context and dynamics. This research note aims to contribute to the debate on international environmental justice by addressing the different relationships that the USA and Europe establish with the EJM and its influence on the relational configuration of their current societal contexts.
\end{abstract}

The environmental justice movement, an important movement with significant political power that emerged around the early ' 80 s, was the result of long local environmental justice struggles and social "bottom-up" grassroots movements in the United States, such as the Clearing House for Hazardous Waste and the Soutbwest Network for Environmental and Economic Justice. The political mobilisation of the movement was rooted in 'legal and political contestation of proposals to site polluting and toxic facilities in predominantly poor and black communities' (Walker and Bulkeley 2006, 655). The movement took a civil rights and social justice approach to environmental problems and has been supported by a substantial North American academic literature that has analysed and criticized unjust environmental practices (see Hofrichter 1993, Bryant 1995 and Edwards et al. 1996).

As noted by Derek Bell, 'it is only very recently that the idea of environmental justice has been "imported" from the United States into social justice and environmental discourses in the UK' (2004, 287). According to Bell, compared with the rest of the world, in the US there is for instance 'a much longer history of research that shows a correlation between low-income groups and pollution', although, it is also known that 'historically, the US environmental justice movement has focused on a narrow community: current US citizens' (2004, 290-291).

One of the most radical groups of the grassroots environmental justice movement - Earth First founded in the US in 1980, has profound anti-institutional and decentralized structures and is fiercely committed to participatory action. But most US grassroots groups are usually formed by residents of a local community with a "not in my back yard" approach to a proposed "local unwanted land use", such as the case of Love Canal residents in New York, an incident of industrial toxic waste dumping in Niagara Falls (1978) (Gibbs, 1982). These groups have a significantly different membership profile compared to the predominant middle-class groups from the mainstream environmental movement. Yet, incapable of operating successfully by themselves, some of these grassroots groups formed networks for co-ordinated action that frequently led to campaigns with a bigger impact. These groups have been most notorious in the US (Gould et al. 1996; Schlosberg 1999) and have emerged from the need to 'share scientific and technical information and learn from each other's experiences and pool resources in jointly resources run campaigns' (Carter 2001, 144).

According to Carter, 'the absence of an equivalent working-class or non-white grassroots environmental justice movement in Europe may reflect different political opportunity structures, notably the more pluralistic nature of the American polity, and the greater possibility in Europe of expressing social justice issues in partisan terms through left-wing or green parties' $(2001,145)$. In fact, US environmental justice movements have been directly related to environmental inequalities arising from issues like class, poverty, race and gender. These are the issues that have formed the basis for the environmental hazards that affect the most vulnerable people. In that sense, and unlike European movements, they become direct political expressions rooted in social 
justice principles. This reinforces the movement dynamic and is translated in the augmentation of the movement strength. As Christopher Rootes writes:

'It is only in the loosest sense that one can speak, even now, of an European environmental movement; the shadows of highly particular national cultures, histories and political structures lie so long across even this most global of concerns that environmental movements are still mainly national, or even regional or local, rather than transnational' (Rootes, 2008: 8).

One of the most recent movements in Europe, the UK anti-roads protests, 'did develop a social justice agenda, but it had a more overtly "green" character than the American environmental justice movement' (Carter 2001, 145). However, just like the EJM it was triggered by 'disillusionment with the perceived ineffectiveness of the mainstream professional environmental groups, especially FoE and Greenpeace' (ibid.). Therefore it is considered by many as 'the first full expression of the new social movement type in British environmental politics' (Doherty 1999, 209).

US policies and terminologies on environmental justice have expanded throughout the world, and although maintaining the strength developed by grassroots and everyday injustice struggles at many political sites, 'in breaking away from its origins and initial framing in the US, the concept of environmental justice is evolving to become broader in scope and more encompassing in the sites, forms and processes of injustice with which it is concerned' (Walker and Bulkeley 2006, 655). This expansion is quickly transferring an important conceptual base into 'policy rhetoric and the work of mainstream institutions operating in varied places and at different scales of governance' (Walker and Bulkeley 2006, 655).

Europe has been seeking inspiration to solve the environmental concerns of the poor from Southern contexts, while the environmental justice movement in the US, as Harvey argues, retain a 'sideways looking admiration for those marginalized peoples who have not yet been fully brought within the global political economy of technologically advanced and bureaucratically rationalized capitalism' (Harvey 1996, 389). But it seems that the US dominant neoliberal context and consequent market mechanisms could be a dangerous source to 'polarize and simplify the experience of marginalized peoples' (Williams and Mawdsley 2006, 661). As a result, most of the EJMs from the west are being pinpointed by narratives of political and academic elites that represent too simplistically the issues at hand. And although there is an effort to find 'a middle ground between "militant particularism" and the theoretical universalism inherent within (ecological) Marxism through a pluralist perspective' (Williams and Mawdsley 2006, 669), the promises that market solutions will solve existing problems is entangling North-South disagreements that have jeopardized the effectiveness of international environmental institutions (see McAfee 1999 and Agyeman et al. 2003).

In the USA neo-liberal dynamics have had more severe consequences than in Europe, which has created a "ping-pong" effect through equally strong bottom-up contextualized action from environmental justice movements, which, through the years, have consistently solidified a dynamic culture of activism strongly ingrained within US capitalism. However, in Europe, the lack of a long history of research, activism and contextualized local action of environmental justice movements is increasing the already strained relation between North and South, to which the hunger for a post-neoliberal model of a heterogeneous and divided Europe is also contributing. According to Manuel Castells:

'Ecologists have long ago identified their objective enemy as the state nationalism. As the nation-state is particularly bound by its need to exercise power over a given territory through internal and external relations it usually undermines the sharing of the global ecosystem' (Castells, 2004: 185). 
In this moment of political, economic and financial instability, European countries compete between themselves for a share in global trade markets. This has allowed their two most powerful and direct competitor nations, the US and China, to compete in the European market regardless of the reciprocity of opportunities they might attain through Europe's shared sovereignty. But most importantly, it has reduced the unification power that has been their main source of strength and global influence for the last half a century. In the light of such circumstances, besides nationalism consequences for the environmental front, i.e. the restricted ability to act transnationally, the spiritual quality of environmentalism and "Green politics" (Kelly 1994: 37) now carry a subversive purpose that can go beyond the instrumentalist perspectives of the past.

It is still uncertain if post-neoliberal forces and market driven solutions will tend to lead the social justice agenda of left wing and green political parties in Europe, and if European environmental justice struggles will become as strong as US "bottom-up" grassroots movements. But, to some extent, the comparison between the strength of the EJM in US and in Europe seems to reinforce the relevance of environmental justice as that one sector which acknowledges the most urgent challenges of a globalized world. And this seems to be true not only due to the importance of historical and current flows of wealth and power between the US and Europe, but mainly because environmentalism supersedes conflictual divisions in cultural, historical, social, religious or gender identities, as it is the only global identity that prevails on behalf of all human beings.

It is also important to note that it has been one century since most of the planet was European colonized territory. Many of the countries that were European colonies, now part of the so called emergent economies, such as Brazil, India and China, are challenging the hegemonic relations between the European Union and the US. Although the existent trade relations between some European countries and their ex-colonies seem to represent an ascendant trend there are major issues that have undermined the process of European transformation and have increasingly eroded social and environmental justice. The massive migration flows of the last century and the difficulties faced by nation-states in controlling the easy mobility of capital and information have transformed the lives of European societies and institutions, which, pressed by the ongoing economic crisis, make evident the still unresolved process of decolonization and the conflicts between the written constitutional democratic right and the actual practice of the state. This has increased xenophobic and racist manifestations, which have emerged in tandem with an identity and welfare state crisis around politics and the European state. While this is leading to a retrenchment of national identity against the European Union, citizens' trust in regional and local levels of governance compared with national and supranational levels show that if European enlightened technocrats are to devise a European project with which citizens agree, then regions and cities, where identity is stronger and democratic governance plays a major role, are the nodes of a European and global polycentric network through which it is still possible to believe in the progress of social and environmental justice. It is often the case that people's sensitivity to the environment starts in the environment where they live, and this is for the great majority of people their local communities.

Also central to EJM is the communication and information technologies revolution. Like many other social movements EJM now have the benefits of interconnectedness and the sharing of information, knowledge and resources between different struggles around the world. And although this might be happening in a spontaneous and perhaps haphazard way, it has the potential to generate, in a rather faster fashion, stronger and better prepared actions that are as diverse as people's personal beliefs and desires.

It is still uncertain whether academic or political universalist tendencies in movements will address the diversified and integral nature of EJMs that civil society demands. But if EJMs are to address a truly social justice agenda in Europe they should use Europe's economic superiority and privileged political and cultural relations with its ex-colonies to grasp the developmental and trade issues coherently, taking a wide perspective on environmental and cultural concerns beyond 
the dominance of scientific knowledge as the only vanguard knowledge. In fact, one of the most empowering subjects within EJMs remains the need to learn from the social contexts of the countries in the global south. More often than not their late industrialization and technological development still retain the ancestral knowledge that industrialized countries from the global north tend to forget and dismiss in the face of their own enhanced productive capacities.

As Boaventura de Sousa Santos argues, making reference to scientific knowledge or scientific Marxism as a privileged knowledge in the 60's: 'Now there is no avant garde. There is no form of knowledge to which we can attribute, in general, an epistemological privilege' (Dalea and Robertson, 2010: 160). And referring to the new role of activists he also argues that 'the quality of the engaged intellectual's contribution lies in her or his capacity to articulate the ecology of knowledges' (Dalea and Robertson, 2010: 160). The notion of the ecology of knowledges is therefore central to the understanding of and learning from the social realities of Europe's excolonies. In opposition to abstract universalism, it seems to carry the intellectual clarity needed to aspire to socio-ecological dignity and emancipation.

Considering the more overtly "green" opportunity structure of the social justice agenda available for EJMs in Europe, which, compared with US EJMs, seem closer to superseding the dialectics that gathered mobilization around the social movements of industrial society, and considering the ability of environmentalism to take on board and go beyond institutional politics and congregate interests on behalf of all forms of life, I would argue that environmental justice is, in Europe, that all-encompassing entity with the strongest potential not only for environmentalism, but also for the resolution of the European project.

(C) Daniel Lobo, 2011 MSc. Urban Studies Department of Geography

\section{Bibliography}

Agyeman, Julian, Bullard, Robert, and Evans, Bob. Just Sustainabilities: Development in an Unequal World. London: Earthscan, 2003.

Bell, Derek, 'Environmental Justice and Rawls' Difference Principle', Environmental ethics, 26.3. 2004. 287-306.

Bryant, Bunyan. Environmental Justice. Boston: Island Press, 1995.

Carter, Neil. The Politics of the Environment: Ideas, Activism, Policy. Cambridge: Cambridge University Press, 2001.

Castells, Manuel. The Power of Identity: Information age, economy, society and culture. Volume 2, Blackwell Publishing, Oxford, 2004.

Dalea, Roger and Robertson, Susan. 'Interview with Boaventura de Sousa Santos'. Globalisation, Societies and Education. 2.2. 2010. 147-160.

Edwards, Sally, Edwards, Terry, and Fields, Charles. Environmental Crime and Criminality: Theoretical and Practical Issues. NewYork and London: Garland Publishing, 1996.

Gibbs, Jack, ed. Social Control: Viens from the Social Sciences. Beverly Hills: Sage, 1982.

Harvey, David. Justice, Nature and the Geography of Difference. Oxford: Blackwell, 1996. 
Hofrichter, Richard, ed. Toxic Struggles: The Theory and Practice of Environmental Justice. Philadelphia: New Society Publishers, 1993.

Kelly, Petra. Thinking Green: Essays on Environmentalism, Feminism, and Nonviolence. Parallax Press, 1993.

McAfee, Kathleen, 'Selling Nature to Save It? Biodiversity and Green Developmentalism', Environment and Planning D: Society and Space, 17.2. 1999. 133-154.

Rootes, Christopher. 1968 and the Environmental Movement in Europe. Palgrave Macmillan, New York, 2008

Schlosberg, David, 'Reconceiving Environmental Justice: Global Movements and Political Theories', Environmental Politics, 13.3. 2004. 515-540.

Walker, Gordon and Bulkeley, Harriet, 'Geographies of Environmental Justice', Geoforum, 37.5. 2006. 655-659.

Williams, Glyn, and Mawdsley, Emma, 'Postcolonial Environment Justice: Government and Governance in India'. Geoforum. 37.5. 2006. 660-670. 